Л.В. Потрашкова

Харківський національний економічний університет ім. С. Кузнеия, Харків

\title{
СИСТЕМАТИЗАЦІЯ КРЕАТИВНИХ ПРИЙОМІВ ПОБУДОВИ ГРАФІЧНОї КОМПОЗИЦІї
}

Мета цьвого дослідження - розробка класифікації типів новизни у графічній композиџї та відповідна систематизація креативних прийомів графічного дизайну. Графічний дизайн розглядається як процес, який має вхід та вихід. На вхід зазначеного прочесу надходить зміст інформачії (повідомлення, теssаgе), який необхідно передати. Виходом (результатом) прочесу є графічна композиція. У роботі виявлено складники графічної композиції та їхні атрибути і на иій основі запропоновано класифікацію типів новизни у графічному дизайні. У відповідність виявленим типам новизни зіставлено групи креативних прийомів. Застосування креативних прийомів проілюстровано на прикладі розробки фірмового графічного стилю для факультету інформаційних технологій ВНЗ.

Ключові слова: графічний дизайн, графічна композиція, креативні прийоми, морфологічний аналіз, розробка фірмового стилю.

\section{Вступ}

Постановка проблеми. Професію графічного дизайнера відносять до творчих професій. Як відомо, під творчістю розуміють процес діяльності, який створює якісно нові матеріальні та/або духовні цінності. Що ж нового створюють дизайнери-графіки? Ocновна функція графічного дизайну - вирішення проблеми комунікації візуальними засобами [1]. Можна сказати, що графічний дизайн - це процес і результат організації графічних елементів на різних носіях 3 метою передачі заданого повідомлення. Так як повідомлення в основному задається замовником, дизайн визначає спосіб передачі цього повідомлення. Саме тут і знаходиться сфера творчості дизайнера: основна новизна в графічному дизайні полягає в тому, щоб передати задане повідомлення якось по-новому.

Аналіз останніх досліджень і публікацій. Питання творчості у графічному дизайні розглядаються у багатьох публікаціях, зокрема [1-12]. Більшість 3 цих публікацій присвячено дизайну реклами. У роботах, серед іншого, розглядаються креативні прийоми у дизайні, а також методи розвитку та активізації творчого мислення дизайнерів. Наявні розробки доцільно доповнити систематизацією відомих креативних прийомів, спрямованою на підвищення зручності їхнього практичного використання.

Мета цієї статті - розробка класифікації типів новизни у графічній композиції та відповідна систематизація (виявлення системи взаємопов'язаних груп) креативних прийомів графічного дизайну.

Під креативним прийомом створення графічної композиції будемо розуміти прийом, який дозволяє додати у цю композицію новизну.

\section{Виклад основного матеріалу}

Будемо розглядати графічний дизайн як процес, який має входи та виходи.
На вхід цього процесу надходить зміст інформації (повідомлення, message), який необхідно передати за допомогою графічної композиції. Задана інформація поділяється на вербальну (текст написів) та невербальну (емоції, враження, асоціації). Зміст інформації може бути сформульований замовником або виявлений дизайнером на етапі передпроєктних досліджень.

Результатом (виходом) процесу, що розглядається, є графічна композиція. Будемо розглядати такі основні складники графічної композиції в аспекті форми:

1. Текст (написи).

Основні атрибути тексту:

- зміст тексту (ЩО написано);

- параметри оформлення тексту (ЯК написано): гарнітура, кегль, колір, використані прийоми виділення, використана техніка створення напису.

2. Зображення (графіка і фото).

Основні атрибути зображення:

- зображені об'єкти (ЩО зображено);

- параметри оформлення графіки або фото (ЯК зображено):

використані композиційні прийоми створення зображення (симетрія, асиметрія, ритм, метр, акцент і т.п.); колірна гама зображення; використана техніка створення зображення.

Виходячи 3 наведених складників графічної композиції та їхніх атрибутів можна запропонувати класифікацію типів новизни у графічній композиції та відповідну систематизацію креативних прийомів у графічному дизайні - табл. 1. Систематизація полягає у тому, що креативні прийоми ставляться у відповідність виявленим типам новизни у графічній композиції. 
Таблиця 1

Класифікація типів новизни та відповідна систематизація креативних прийомів у графічному дизайні

\begin{tabular}{|c|c|}
\hline $\begin{array}{c}\text { Класифікація } \\
\text { типів новизни } \\
\text { у графічній композицій }\end{array}$ & $\begin{array}{c}\text { Приклади } \\
\text { відповідних } \\
\text { креативних прийомів }\end{array}$ \\
\hline $\begin{array}{l}\text { 1. Оригінальне офор- } \\
\text { млення написів }\end{array}$ & $\begin{array}{l}\text { каліграфія; } \\
\text { летеринг }\end{array}$ \\
\hline \multicolumn{2}{|l|}{$\begin{array}{l}\text { 2. Незвичайні зобра- } \\
\text { ження }\end{array}$} \\
\hline $\begin{array}{l}\text { 2.1. Незвичайне поєд- } \\
\text { нання звичайних зо- } \\
\text { бражень об’єктів, про } \\
\text { які йде мова у заданому } \\
\text { повідомленні }\end{array}$ & $\begin{array}{l}\text { поєднання за контрас- } \\
\text { том; } \\
\text { поєднання за схожістю }\end{array}$ \\
\hline $\begin{array}{l}\text { 2.2. Модифікація зо- } \\
\text { браження об’єктів, про } \\
\text { які йде мова у заданому } \\
\text { повідомленні }\end{array}$ & $\begin{array}{l}\text { зміна забарвлення; } \\
\text { зміна напису; } \\
\text { гібрид; } \\
\text { трансформація } \\
\text { (звуження, розтягнення } \\
\text { й т.п.); } \\
\text { заміна частини; } \\
\text { додавання нових еле- } \\
\text { ментів }\end{array}$ \\
\hline $\begin{array}{l}\text { 2.3. Метафоричне ви- } \\
\text { користання зображень } \\
\text { інших об'єктів (відмін- } \\
\text { них від тих, про які йде } \\
\text { мова у заданому повід- } \\
\text { омленні) }\end{array}$ & $\begin{array}{l}\text { візуальна метафора, } \\
\text { символи }\end{array}$ \\
\hline $\begin{array}{l}\text { 2.3.1) немодифікова- } \\
\text { ні метафоричні зо- } \\
\text { браження; } \\
\text { незвичайне поєднан- } \\
\text { ня немодифікованих } \\
\text { зображень об'єктів }\end{array}$ & - \\
\hline $\begin{array}{l}2.3 .2) \text { модифіковані } \\
\text { метафоричні зобра- } \\
\text { ження }\end{array}$ & яку \\
\hline $\begin{array}{l}\text { 2.4. Застосування ори- } \\
\text { гінальних прийомів } \\
\text { побудови композиції }\end{array}$ & $\begin{array}{l}\text { прийом негативного } \\
\text { простору; } \\
\text { прийом подвійного } \\
\text { змісту; } \\
\text { складання зображення з } \\
\text { множини інших; } \\
\text { стилізація }\end{array}$ \\
\hline $\begin{array}{l}\text { 2.5. Застосування ори- } \\
\text { гінальної техніки ство- } \\
\text { рення зображення }\end{array}$ & $\begin{array}{l}\text { каліграма; } \\
\text { поєднання малюнку та } \\
\text { фотографії }\end{array}$ \\
\hline $\begin{array}{l}\text { 3. Оригінальне посд- } \\
\text { нання звичайного зо- } \\
\text { браження та звичай- } \\
\text { ного напису }\end{array}$ & $\begin{array}{l}\text { гра слів, яка базується } \\
\text { на однаковому } \\
\text { написанні різних слів }\end{array}$ \\
\hline
\end{tabular}

Джерело: розроблено автором.
Приклади застосування деяких зі згаданих у табл. 1 креативних прийомів наведено на рис. 1-7.

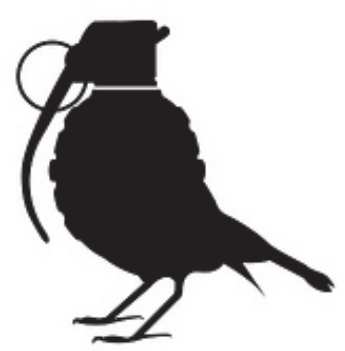

Рис. 1. Модифікація зображення: гібрид (соціальна реклама Pro Wildlife)

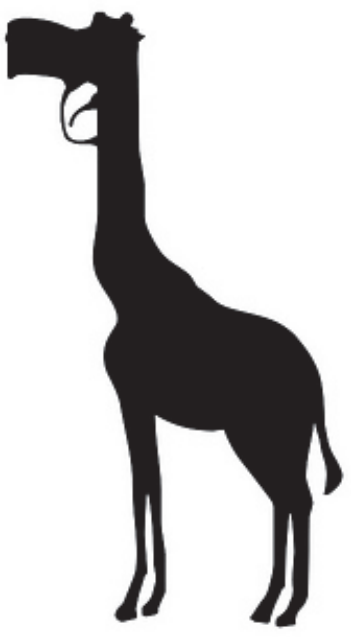

Рис. 2. Модифікація зображення: гібрид (соціальна реклама Pro Wildlife)

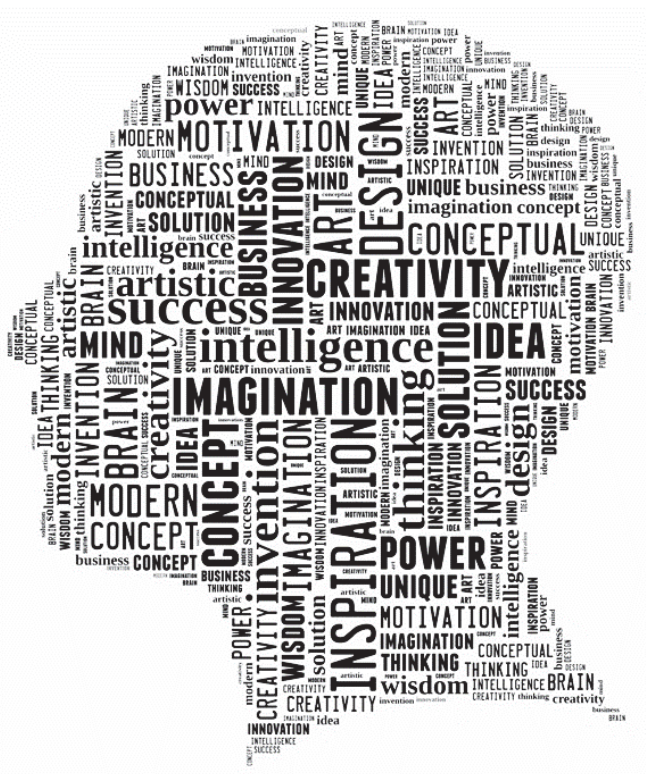

Рис. 3. Каліграма 


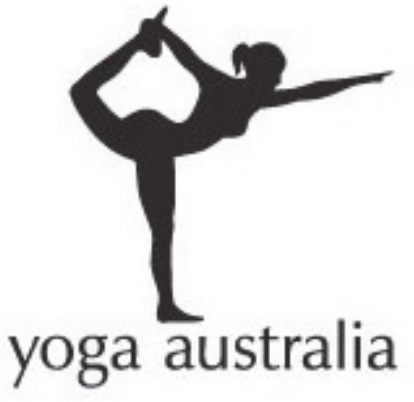

Рис. 4. Прийом негативного простору (фірмовий знак Yoga Australia)

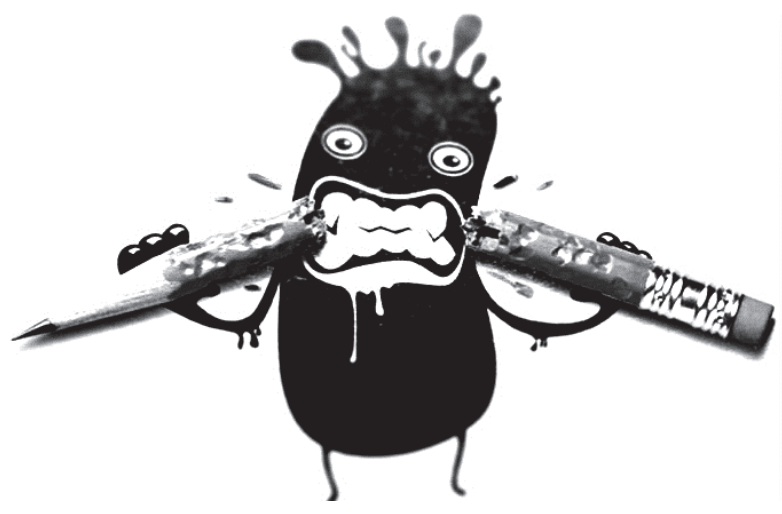

Рис. 5. Оригінальна техніка створення зображення: поєднання малюнку та фотографії

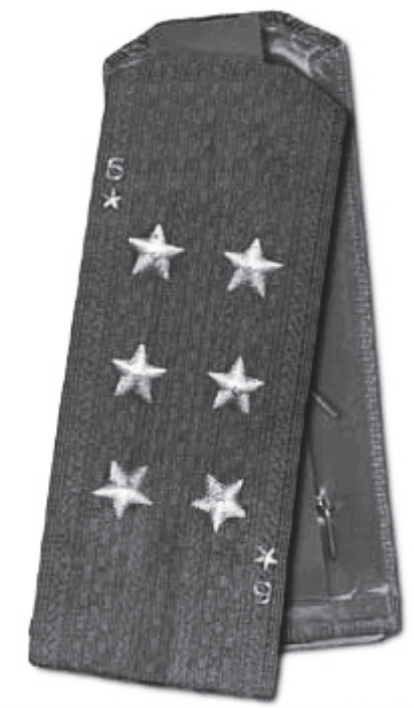

\section{ЧЕРЕЗ ТЕРНИИ - К ЗВЁЗДАМ!}

Рис. 6. Звичайне зображення + звичайний текст + незвичайне їхнє поєднання Джерело: [2-3].

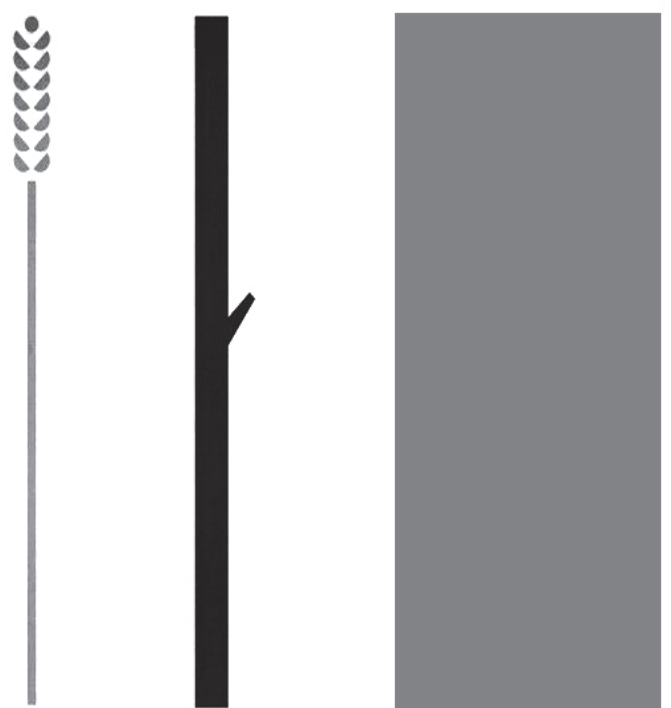

\section{THETHREE LITLEPISS}

Рис. 7. Використання символів (постер до казки “Три порося”)

Приклад застосування креативних прийомів у графічному дизайні. Поширеним напрямом графічного дизайну $є$ розробка графічного стилю для фірми або особи. Графічний стиль фірми (персони) - це сукупність графічних елементів і прийомів, які створюють постійний візуальний образ фірми (персони) за рахунок того, що забезпечують стилістичну єдність зовнішнього вигляду об'єктів, що мають відношення до цієї фірми (персони): реклами, продукції, пакування, документації, приміщень і т.п.

Центральний елемент графічного стилю - знак (логотип).

До фірмових та персональних знаків висуваються такі вимоги:

- унікальність (знак має бути оригінальним, неповторним);

- значимість (знак має передавати відмітні характеристики фірми або персони);

- лаконічність (знак має зчитуватися глядачем за пару секунд);

- запам'ятовуваність (знак має стійко асоціюватися 3 певною фірмою або персоною);

- естетичність (знак має викликати у глядача позитивні відчуття гармонії);

- відтворюваність (знак має зберігати гарний вигляд і характерний образ при використанні різних технологій друку та різних носіїв);

- масштабованість (знак має зберігати гарний вигляд і характерний образ і у великому, і у маленькому розмірі).

Виділимо такі етапи розробки фірмового (персонального) знаку: 
1. Визначення того, ЩО повинно бути зображено на фірмовому знаку.

1.1. Виявлення понять, вражень, асоціацій, які повинні бути передані в знаку.

1.2. Виявлення візуальних символів, образів, які дозволять візуалізувати задані поняття, враження, асоціації.

2. Визначення вимог до зовнішнього вигляду знака (тобто визначення того, ЯК повинен виглядати знак).

2.1. Формування та вибір варіантів поєднання візуальних символів, виявлених на етапі 1.

2.2. Виявлення та вибір графічних прийомів, які можуть бути застосовані для створення знака.

2.3. Обгрунтування колірної гами знака.

Так як найважливішою вимогою до фірмового (персонального) знаку $є$ його унікальність, під час його розробки доцільним $є$ використання креативних прийомів. Розглянемо застосування креативних прийомів на прикладі розробки знаку (емблеми) для факультету інформаційних технологій вищого навчального закладу. Вважаємо, що знак має передавати таке повідомлення: "На факультеті навчають новітнім інформаційним технологіям, які здійснюють інформаційну підтримку управління бізнесом". Результати виконання першого етапу розробки знаку факультету інформаційних технологій наведено у табл. 2.

Таблиця 2

Морфологічна таблиця варіантів об’єктів, які доцільно зобразити

на знаку факультету інформаційних технологій

\begin{tabular}{|l|l|}
\hline \multicolumn{1}{|c|}{$\begin{array}{c}\text { Перелік понять, } \\
\text { вкажень, асоціацій, } \\
\text { ні в вунаку }\end{array}$} & $\begin{array}{c}\text { Візуальні символи, } \\
\text { образи, які дозволять } \\
\text { візуалізувати задані } \\
\text { поняття }\end{array}$ \\
\hline $\begin{array}{l}\text { інформаційні } \\
\text { технології }\end{array}$ & $\begin{array}{l}\text { комп'ютер; клавіатура; } \\
\text { монітор; комп'ютерна } \\
\text { миша; системний блок; } \\
\text { база даних; діаграми; } \\
\text { смартфон }\end{array}$ \\
\hline $\begin{array}{l}\text { новітні } \\
\text { інформаційні } \\
\text { технології }\end{array}$ & $\begin{array}{l}\text { робот; шолом віртуаль- } \\
\text { ної реальності; смарт- } \\
\text { фон із зображеннями з } \\
\text { доповненої реальності }\end{array}$ \\
\hline $\begin{array}{l}\text { інформаційна } \\
\text { підтримка } \\
\text { прийняття рішень }\end{array}$ & $\begin{array}{l}\text { маяк; } \\
\text { рятувальний круг; } \\
\text { компас }\end{array}$ \\
\hline бізнес & $\begin{array}{l}\text { підприємство; } \\
\text { гроші; сейф; } \\
\text { портфель }\end{array}$ \\
\hline успіх & $\begin{array}{l}\text { усмішка; } \\
\text { графік вгору; } \\
\text { яскраві кольори }\end{array}$ \\
\hline
\end{tabular}

Джерело: розроблено автором.
Далі необхідно сформувати варіанти зовнішнього вигляду знаку факультету. Для цього звернемось до запропонованого переліку типів креативних прийомів (табл. 1). Шляхом перебору зазначених типів прийомів сформуємо набір варіантів зображення на знаку факультету. Результат застосування запропонованого підходу наведено у табл. 3

Таблиця 3

Варіанти зображень на знаку факультету, отримані за допомогою застосування креативних прийомів

\begin{tabular}{|c|c|}
\hline $\begin{array}{c}\text { Типи новизни } \\
\text { та креативні прийоми }\end{array}$ & $\begin{array}{l}\text { Варіанти зображень } \\
\text { на знаку факультету }\end{array}$ \\
\hline 1 & 2 \\
\hline $\begin{array}{l}\text { 1. Оригінальне офор- } \\
\text { млення написів }\end{array}$ & $\begin{array}{l}\text { Складення напису “ІІн- } \\
\text { формаційні технології” } \\
3 \text { деталей комп”ютера }\end{array}$ \\
\hline
\end{tabular}

\section{2. Оригінальні зображення}

2.1. Незвичайне поєд- Людина та робот потинання звичайних зо- скають один одному бражень об'єктів, про руки

які йде мова у заданому

повідомленні

2.2. Модифікація зображення об'єктів зі сфери IT

\begin{tabular}{|l|l|}
\hline зміна текстури & Монітор і клавіатура із
\end{tabular}

\begin{tabular}{|l|l|} 
& мармуру \\
\hline зміна напису & Комп'ютерна клавіату-
\end{tabular}

\begin{tabular}{l|l} 
зміна напису & ра, на якій замість ал-
\end{tabular} фавіту написано "успіх"

зміна кольору Комп’ютерна миша, розфарбована як шкура леопарда

2.3. Метафоричне використання зображень об'єктів не зі сфери IT

незвичайне поєднання Компас на екрані комнемодифікованих зо- п'ютера; пейзаж, у якображень му замість сонця світить монітор комп'ютера; робот із портфелем;

\begin{tabular}{l|l}
\hline гібрид & Гібрид системного
\end{tabular} блоку з сейфом

додавання нових еле- Зображення підприємс\begin{tabular}{l|l} 
ментів & тва 3 USB-портом, до
\end{tabular} якого підключено комп'ютерну мишу

\begin{tabular}{l|l}
\hline зміна напису & Рятувальний круг з на-
\end{tabular}
писом "IT"

2.4. Застосування оригінальних прийомів побудови композиції

складання зображення з множини інших вікнах, які складаються 3 множини моніторів ефект подвійного Зображення смартфону, змісту який у той же час $є$ дверима до нового простору 
Закінчення табл. 3

\begin{tabular}{|l|l|}
\hline \multicolumn{1}{|c|}{1} & \multicolumn{1}{|c|}{2} \\
\hline $\begin{array}{l}\text { 2.5. Застосування ори- } \\
\text { гінальної техніки ство- } \\
\text { рення зображення }\end{array}$ & $\begin{array}{l}\text { Створення зображення } \\
\text { робота у техніці каліг- } \\
\text { рами }\end{array}$ \\
\hline $\begin{array}{l}\text { 3. Оригінальне посд- } \\
\text { нання звичайного 30- } \\
\text { браження та звичай- } \\
\text { ного напису }\end{array}$ & $\begin{array}{l}\text { ра з написом “зброя 21 } \\
\text { столт” [2-3] }\end{array}$ \\
\hline
\end{tabular}

Джерело: розроблено автором.
Висновки

У роботі здійснено систематизацію типів новизни та креативних прийомів у графічному дизайні. Отриманий результат формує шаблон для перебору варіантів застосування креативних прийомів 3 метою активізації та підтримки креативного мислення людини для вирішення завдань у сфері графічного дизайну. Здійснені розробки можуть отримати подальший розвиток у напрямі врахування особливостей різних сфер графічного дизайну.

\section{Список літератури}

1. Эверс В., Кендра Э. Искусство дизайна - с компьютером и без... Москва : Кудиц-Образ, 2004. 198 с.

2. Пронин С. Рекламная иллюстрация: креативное восприятие. Москва : Бератор-Пресс, 2003. 142 с.

3. Пронин С. Рекламисту о дизайне. Дизайнеру о рекламе. Москва : Бератор, 2004. 168 с.

4. Павловская Е. Э. Дизайн рекламы (Стратегия проектного творчества) : дис. ... д-ра искусствоведения : 17.00.06. Москва, 2003. 484 с.

5. Павловская Е. Э. Дизайн рекламы: поколение NEXT. Стратегия творческого проектирования. Санкт-Петербург : Питер, 2003. $318 \mathrm{c.}$

6. Туэмлоу Э. Графический дизайн: фирменный стиль, новейшие технологии и креативные идеи. Москва : Астрель, ACT, 2006. $256 \mathrm{c}$

7. Альмомани Х. Н., Быстрова Т. Ю. Алгоритмы дизайн-мышления: теория и практика. Академический вестник УралНИИпроект. 2019. № 2. С. 92-97. https://doi.org/10.25628/UNIIP.2019.41.2.017.

8. Hrabovskyi Y., Brynza N., Vilkhivska O. Development of information visualization methods for use in multimedia applications. EUREKA: Physics and Engineering. 2020. № 1. P. 3-17. https://doi.org/10.21303/2461-4262.2020.001103.

9. Hrabovskyi Y., Yevsyeyev O., Pandorin A. Development of a method for the creation of $3 \mathrm{~d}$ advertising printing products. Eastern-European Journal of Enterprise Technologies. 2018. № 6/2(96). P. 6-18. https://doi.org/10.15587/17294061.2018.147325.

10. Lowson B. How Designers Think. The design process demystified. Elsivier, 2005. 336 p.

11. Clark K., Smith R. Unleashing the power of design thinking. Design Management Review. 2010. № 19(3). P. 8-15. https://doi.org/10.1111/j.1948-7169.2008.tb00123.x.

12. Harland R. The dimensions of graphic design and its spheres of influence. Design Issues. № 27(1). P. 21-34. https://doi.org/10.1162/DESI_a 00054 .

\section{References}

1. Evers, V. and Kendra, E. (2004), "Iskusstvo dizajna - s komp'yuterom i bez..." [The art of design - with or without a computer], Kudic-Obraz, Moscow, 198 p.

2. Pronin, S. (2003), "Reklamnaya illyustraciya: kreativnoe vospriyatie" [Advertising illustration: creative perception], Berator-Press, Moscow, 142 p.

3. Pronin, S. (2004), "Reklamistu o dizajne. Dizajneru o reklame" [For an advertiser about design. For a designer about advertising], Berator, Moscow, $168 \mathrm{p}$.

4. Pavlovskaya, E. (2003), "Dizajn reklamy (Strategiya proektnogo tvorchestva): dysertacija" [Advertising design (Strategy of design creativity): dissertation], Moscow, $484 \mathrm{p}$.

5. Pavlovskaya, E. (2003), "Dizajn reklamy: pokolenie NEXT. Strategiya tvorcheskogo proektirovaniya" [Advertising design: generation NEXT. Strategy of creative design], Piter, St. Petersburg, 318 p.

6. Tuemlou, E. (2006), "Graficheskij dizajn: firmennyj stil', novejshie tekhnologii i kreativnye idei" [Graphic design: corporate identity, the latest technologies and creative ideas], Astrel', AST, Moscow, 256 p.

7. Al'momani, H. and Bystrova, T. (2019), "Algoritmy dizajn-myshleniya: teoriya i praktika" [Design thinking algorithms: theory and practice], Akademicheskij vestnik UralNIIproekt, No. 2, pp 92-97. https://doi.org/10.25628/UNIIP.2019.41.2.017.

8. Hrabovskyi, Y., Brynza, N. and Vilkhivska, O. (2020), Development of information visualization methods for use in multimedia applications, EUREKA: Physics and Engineering, No. 1, pp. 3-17. https://doi.org/10.21303/2461-4262.2020.001103.

9. Hrabovskyi, Y., Yevsyeyev, O. and Pandorin, A. (2018), Development of a method for the creation of $3 \mathrm{~d}$ advertising printing products, Eastern-European Journal of Enterprise Technologies, No. 6/2(96), pp. 6-18. https://doi.org/10.15587/17294061.2018.147325.

10. Lowson, B. (2005), How Designers Think. The design process demystified, 4th ed., Elsivier, $336 \mathrm{p}$.

11. Clark, K. and Smith, R. (2010), Unleashing the power of design thinking, Design Management Review, No. 19(3), pp. 8-15. https://doi.org/10.1111/j.1948-7169.2008.tb00123.x.

12. Harland, R. (2011), The dimensions of graphic design and its spheres of influence, Design Issues, No. 27(1), pp. 21-34. https://doi.org/10.1162/DESI_a_00054 


\section{Відомості про авторів:}

Потрашкова Людмила Володимирівна кандидат економічних наук

доцент

доцент Харківського національного економічного університету ім. С. Кузнеця, Харків, Україна

https://orcid.org/0000-0002-8239-2794
Information about the authors:

Liudmyla Potrashkova

Candidate of Economic Sciences

Associate Professor Senior Lecturer

of Simon Kuznets Kharkiv National

University of Economics,

Kharkiv, Ukraine

https://orcid.org/0000-0002-8239-2794

\title{
СИСТЕМАТИЗАЦИЯ КРЕАТИВНЫХ ПРИЕМОВ ПОСТРОЕНИЯ ГРАФИЧЕСКОЙ КОМПОЗИЦИИ
}

\author{
Л.В. Потрашкова
}

Цель этого исследования - разработка классификации типов новизны в графической композиции и соответствуюшая систематизаиия креативных приемов графического дизайна. Графический дизайн рассматривается как проиесс, имеющий вход и выход. На вход указанного прочесса поступает содержание информации (сообщение, теssаgе), который необходимо передать. Выходом (результатом) проиесса является графическая композииия. В работе выявлены составляющие графической композищии и их атрибуты и на этой основе предложена классификация типов новизны в графическом дизайне. В соответствии выявленным типам новизны сопоставлены группь креативных приемов. Применение креативных приемов проиллюстрировано на примере разработки фирменного графического стиля для факультета информаиионных технологий вуза.

Ключевые слова: графический дизайн, графическая композиция, креативные приемы, морфологический анализ, разработка фирменного стиля.

\section{SYSTEMATIZATION OF CREATIVE TECHNIQUES OF GRAPHIC COMPOSITION CONSTRUCTION}

\section{Potrashkova}

Subject of research - creative techniques in graphic design. The purpose of this study is to develop a classification of types of novelty in graphic composition and the corresponding systematization of creative techniques in graphic design.

Graphic design is seen as a process that has input and output. The input of this process receives the content of information (message), which must be transmitted. The output (result) of the process is a graphic composition.

Under the creative technique in graphic design we understand a technique that allows one to bring novelty to this composition. Therefore, to identify groups of creative techniques, it is necessary to identify possible types of novelty in graphic compositions. And the types of novelty in the composition can be distinguished depending on which components of the composition are presented in a new way (i.e. are changed compared to traditional versions).

The components of graphic composition and their attributes are revealed in the work and on this basis the classification of types of novelty in graphic design is offered. In accordance with the identified types of novelty, groups of creative techniques are selected. The formed set of types of novelty and corresponding creative techniques forms a certain template for the morphological analysis of a graphic composition, which is developed. This template allows one to organize and activate creative thinking while solving problems in the field of graphic design.

The application of the proposed template (which contains a set of types of novelty in graphic composition and a list of relevant creative techniques) is illustrated by the example of developing a corporate graphic style for the Faculty of Information Technology of higher education institution. The implemented developments can be further developed in the direction of taking into account the features of different areas of graphic design.

Keywords: graphic design, graphic composition, novelty, creative techniques, morphological analysis, graphic corporate identity. 